\title{
Masculinidades monstruosas. Narcocultura, narcoviolencia y sicariato en el México contemporáneo
}

\author{
Vladimir Guerrero Heredia \\ Universidad Autónoma de Chihuahua \\ clasesvladimirguerrero@gmail.com
}

Las imágenes deben asombrarnos. El "performance", el escenario, deben reasignarnos ética y políticamente: Sinaloa, México 31 de octubre de 2019. En el contexto de la celebración del día de Hallowen, a través de los pasillos de un mall o centro comercial, una madre guía en un paseo sereno a su hijo disfrazado terroríficamente para la ocasión. Algunos -según se puede verificar en la gran cantidad de videos que circulan por las redes sociales- lo miran desconcertados y otros ni siquiera reparan en su particular atuendo. El niño reproduce un acto performático -común ya en gran parte del mundo para estas fechas- donde niños y niñas representan un imaginario propio de los capitales estéticos del horror dentro de la cultura de masas y de la cultura popular contemporáneas de occidente: Frankensteines, Dráculas, Zombies, Momias, Brujas, Hombres Lobo o personajes reconocidos de series o películas.

La discontinuidad con lo anteriror radica en que el infante (de aproximadamente seis u ocho años) a quien aquí dirijo mi mirada nos sigue recordando el inquietante desplazamiento, la constante deterritorialización que la narcocultura y la narcoviolencia brutal del México actual nos muestran al continuar en el devenir de escenarios extremadamente ambiguos, desconcertantes y complejos. El niño viste una camisa negra con una gruesa cadena al cuello; unos bluejeans deslavados -rotos a la altura de la rodilla izquierda- y un par de mocasines negros: su "disfraz" performático emula la imagen del joven sicario mexicano contemporáneo, tal vez aquella que pudo sedimentarse profundamente en el imaginario popular sinaloense a través de aquel líder conocido como el "Chino Ántrax", jefe por muchos años del grupo de sicarios del "Cartel de Sinaloa" conocidos como "Los Ántrax", o en un estrato que también puede reconocerse en lo que popularmente se ha resignificado como la cultura "buchona".

Dentro de las distintas e impresionantes images de este "niño-sicario" mexicano que han circulado por la web, hay una en especial que me ha movido a pensar en el inicio precoz de las subjetividades monstruosas propias de este imaginario narco-mexicano contemporáneo. Pienso en una terrorífica gesta del "erostratismo" en nuestras propias masculinidades monstruo. Desde este "locus/imago" trazo el objetivo del presente material como una persistencia crítica que busca continuar el estudio de lo 


\section{Adiós a las armas}

Despatriarcar América desde la cultura

que he denominado: la "configuración monstruosa del sicario mexicano" y en esta ocasión problematizaremos al respecto desde el texto "If you tolerate this your children will be next" incluido dentro del libro de crónicas: El Karma de vivir al norte del escritor mexicano Carlos Velázquez. ${ }^{2}$

Me ocuparé aquí de continuar rescatando la emergencia que distintos dispositivos culturales, relacionados a la narcocultura mexicana y a la narcoviolencia extrema vinculada con los carteles mexicanos, expresan desde distintas manifestaciones terribles hasta en variados y arriesgados ejercicios culturales que hibridan con los capitales estéticos del horror, bastante reconocibles dentro de la cultura de masas o de la cultura popular. Especialmente, me interesa continuar el trazado de estas configuraciones de lo monstruoso en materialidades culturales que permiten distinguir o hasta separar una posible heroificación/exaltación romantizada del sicario mexicano de una configuración particular que se extiende a los territorios propios de: lo anómalo, lo horrible, lo abyecto, lo oscuro, lo siniestro, lo bestial y lo macabro.

Regreso entonces a la imagen especial que ha llamado más mi atención: el niño disfrazado de sicario. La personificación de este infante quedaría así completa cuando nos percatamos de la macabra carga que éste desplaza a lo largo del centro comercial. En los videos puede verse, también, que el niño lleva fajada a la cintura una pistola escuadra (supongo de juguete) y arrastra a sus espaldas una bolsa negra que simula ser el cadáver envuelto de una de sus víctimas, síntoma/rasgo inequívoco del personaje que se ha intentado emular. La image, pues, específica a la que me refiero: nos muestra al "sicario" ejecutor con la pierna izquierda sobre la macabra bolsa negra, su mano izquierda sosteniendo las cachas de su arma asesina y dirigiendo una mirada amenazante, brutal hacia la cámara que lo ha incitado a posar.

1 Véase también mi artículo: "Hibridaciones y desterritorialización: entre el horror sobrenatural y la narcoviolencia mexicana. Imágenes-Monstruo: Narcozombies en la novela Ciudad de Zombis de Homero Aridjis".

2 Este artículo es una versión especial parte del proyecto que será publicado bajo el título de: El narcogótico mexicano - dispositivos culturales del horror y la violencia en el México del Siglo XXI-. Como contexto a este trabajo, ofrezco la definición del "narcogótico mexicano":

Una herramienta teórico-crítica conformada por el carácter híbrido de diversos materiales culturales, tales como: narrativa, música, teatro, cine, televisión, pintura, performances, modas, artículos decorativos, iconografías, fenómenos de internet, videografías, etc., que son representados a través de características temáticas y formales como: la muerte, lo monstruoso, los lugares malditos, lo diabólico, lo fantasmal, el cuerpo mutilado, la tortura, el dolor, entre otras y pertenecientes todas a la tradición estética de lo sublime. El "narcogótico mexicano" está enmarcado por las “experiencias límite” generadas por la narcoviolencia extrema del México contemporáneo y por las constantes intersecciones entre la realidad, el horror sobrenatural y la tradición del horror en la cultura de masas moderna o contemporánea. Con lo anterior se pone en movimiento el trabajo de críticos y artistas que se ocupan del carácter ético-político de la violencia y el narco en el territorio mexicano contemporáneo. 


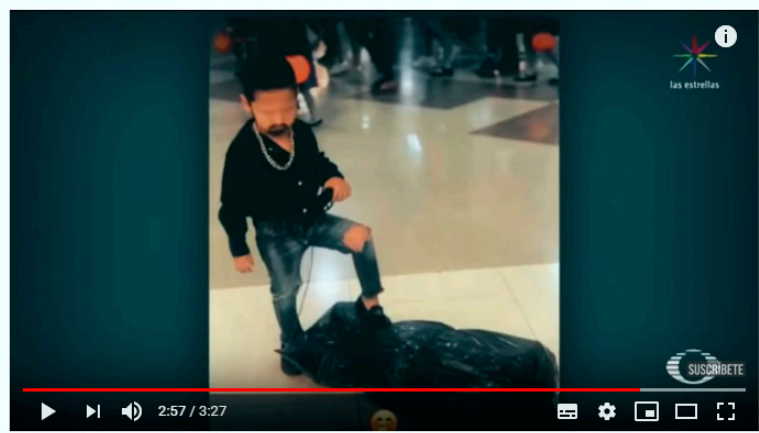

Halloween en Culiacán | Niño disfrazado de sicario en Culiacán - En Punto

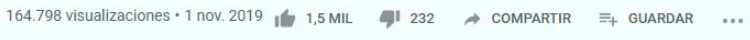

Fig. 1. Video Halloween en Culiacán. Niño disfrazado de sicario.

La imagen y el video de este "niño sicario" me son escalofriantes porque me recuerdan un acontecimiento peor de estremecedor, pero dolorosamente cercano en sus fronteras y en sus condiciones semiótico-culturales. Me refiero a los acontecimientos sucedidos en mayo del 2015 en la Ciudad de Chihuahua, Chih. México. El jueves 14 de mayo cinco adolescentes (uno de once años, dos de quince y dos mujeres de trece) jugaban a ser sicarios y decidieron incluir en su juego macabro al niño Cristopher Raymundo Márquez Mora de seis años a quien en un terreno despoblado ataron y torturaron. El reporte policíaco brindado por los medios de información (Aristegui Noticias, "Tragedia en Chihuahua"; "Niños juegan a ser sicarios”) decía que el cadáver de Cristopher fue localizado el sábado 16 de mayo, cerca de un arroyo donde lo habían semi-sepultado, cubierto con maleza y restos de un animal muerto. Su cuerpo presentaba heridas de arma blanca, golpes en el rostro con piedras y sofocamiento. Los niños y las niñas que jugaron en el 2015 a ser sicarios y sicarias vivían en la colonia Laderas de San Guillermo, una de las tantas colonias marginadas, además de precarizadas de esta ciudad. Los adolescentes fueron descubiertos porque uno de ellos en su arrepentimiento decidió contarle lo sucedido a su madre y quien fue la que informó todo a las autoridades. Jugar con el asesinato, con el imaginario de lo criminal y con lo macabro es uno más de los múltiples rasgos preocupantes que durante más de una década siguen reapareciendo fantasmáticamente en el México de la "máquina narco".

Es justamente este carácter fantasmal y sobrenatural lo que determina la atmósfera completa en la que se desenvuelve el relato de Carlos Velázquez. El coahuilense hace patente en su crónica angustiada uno de los miedos más profundos que pueden volverse realidad para cualquier mexicano que habita en las inestables, y por eso espantosas, narcozonas del norte mexicano: el encuentro material con el "necropoder" representado directamente en la figura del sicario. El relato "If you tolerate this your children will be next”de Velázquez inicia precisamente así: "Una 


\section{Adiós a las armas}

Despatriarcar América desde la cultura

noche, por fin, mis peores temores se cristalizaron. Tuve un encuentro con un sicario." (175). El autor, quien en todo su libro nos ofrece veinticinco estampas estremecedoras de lo que es vivir en el norte mexicano en la época de la narcoviolencia extrema, nos especifica en el primer párrafo de dicho relato testimonial que no era la primera vez que se encontraba con las subjetividades criminales al servicio de los cárteles del narcotráfico mexicano:

No era la primera vez que topaba a uno. Solía encontrármelos en los burritos de hielera de la deportiva los sábados a las dos de la mañana. En la fila del banco, Oxxos, semáforos en rojo, en el estadio de futbol. Cargando gasolina. O en bares y cantinas de mala muerte. Hasta en la barra del Applebee's. Bastaba con güacharles la pinta, el paradillo, para saber que estaban al servicio de la delincuencia. Eran oficiosos, listos, entregados. Y estaban morros (175).

De hecho, esta separación introductoria que el mismo Velázquez nos hace saber de la condición diferencial entre los encuentros comunes, cotidianos con los jóvenes sicarios seducidos por el poder del narco y entre el encuentro tenebroso que está a punto de narrarnos; es lo que determina el derrotero del presente análisis. Pues, el tipo de sicario con el que él y su pequeña hija tendrán la lamentable suerte de encontrarse, es un tipo de asesino que configura su subjetividad asesina desde la exacerbación de lo anormal, de lo abyecto y de lo horrorífico. Será una subjetividad monstruosa: una particular masculinidad exaltada/exacerbada del México contemporáneo que Sayak Valencia clasifica como el tipo de sujetos y prácticas resultado de las reinterpretaciones machistas del neoliberalismo extremo con consecuencias sociales fatales de devenires gore/snuff en todo el territorio nacional. Proceso complejo - esta producción de subjetividades monstruosas- que obedece (según Valencia) a una reproducción acrítica del proyecto de modernidad basado en los conceptos difusos e ilusorios de progreso y ascensión social que han terminado por forjar un performance de género machista perpetuadora de masculinidades hegemónicas, ya tradicionales, que además son redistribuidas diariamente entre los varones mexicanos desde una plataforma bio/necropolítica a través del Estado y la sociedad (la iglesia, los mass media, la familia, la economía, la cultura popular/ narco cultura, etc.) de manera normalizada ("Teoría transfeminista para el análisis de la violencia").

Si uno de los problemas centrales para el desmontaje de las "masculinidades hegemónicas" -tal como en 1998 lo señalara Jack Halberstam- es evidenciar el silenciamiento, la invisibilidad o la marginación de las "masculinidades alternativas" (femeninas, disminuidas/insuficientes, precarizadas, racializadas, minoritarias). El juicio de Halberstam sigue convocando a la reflexión, puesto que es evidente que en gran parte de las sociedades occidentalizadas/colonizadas: 
[...] la masculinidad se asocia a valores de poder, legitimidad y privilegio; a menudo se la vincula, simbólicamente, al poder del Estado y a una desigual distribución de la riqueza. La masculinidad parece difundirse hacia fuera en el patriarcado y hacia dentro en la familia; la masculinidad representa el poder de heredar, el control del intercambio de las mujeres y la esperanza del privilegio social (01).

Desde ahí, entonces, que el grave problema de las masculinidades monstruosas del sicario mexicano deba continuar siendo uno de los ejes centrales dentro de los estudios de género. Pues, tanto la corrupción del Estado mexicano como el necroempoderamiento que representa la narcomáquina mexicana vienen a conjuntar una fórmula sangrienta que sigue potenciando la configuración de subjetividades hiperviolentas alentadas y cegadas por las promesas de: riqueza, poder, hiperconsumo, admiración social, híper privilegios, etc. Por ello, en: "[...] todo argumento a favor de erradicar la violencia criminal debe tener en cuenta que ésta es uno de los valores estructurales en la axiología heteropatriarcal y, por tanto, que las estrategias para combatirla deben hacer énfasis en un análisis crítico de la construcción del género (masculino) en México" (Valencia, "Teoría transfeminista" 72).

En el mismo sentido, lo que he denominado la configuración monstruosa del sicario mexicano recibe un tratamiento específico en el andamiaje epistemológico que Sayak Valencia ha estructurado bajo la reconocida categoría del Capitalismo Gore; me refiero al devenir de los nuevos sujetos del capitalismo brutal contemporáneo que produce, que gesta estas nuevas subjetividades bárbaras que Valencia bautiza como sujetos endriagos:

[...] formulamos el término endriago, para hablar de estas subjetividades capitalísticas que surgen en el contexto del capitalismo gore. Lo hacemos así, pensando en la pertinencia de la tesis de Mary Louise Pratt, quien afirma que el mundo contemporáneo está gobernado por el retorno de los monstruos (Pratt 2002, 1). El endriago es un personaje literario, un monstruo, cruce de hombre, hidra y dragón. Se caracteriza por su condición bestial. Es uno de los enemigos a los que se tiene que enfrentar Amadís de Gaula. [...] Proponemos esta analogía entre el endriago (como personaje literario que pertenece a los Otros, a lo no aceptable, al enemigo) y las subjetividades capitalísticas y violentas representadas por los criminales mexicanos. Lo hacemos así porque consideramos fundamental tomar en cuenta que la construcción del endriago se basó en una óptica colonialista que sigue presente en muchos territorios del planeta considerados como ex-colonias y que recae sobre las subjetividades capitalísticas tercermundistas por medio de una recolonización económica que se afianza a través de demandas de producción e hiperconsumo globales, creando nuevos sujetos ultra violentos y demoledores que 


\section{Adiós a las armas}

Despatriarcar América desde la cultura

conforman las filas del capitalismo gore y del narcotráfico como uno de sus principales dispositivos.

Y a lo que también cabe agregar:

Entendemos a los sujetos endriagos como un conjunto de individuos que circunscriben una subjetividad capitalística, pasada por el filtro de las condiciones económicas globalmente precarizadas, junto a un agenciamiento subjetivo desde prácticas ultraviolentas que incorporan de forma limítrofe y autorreferencial "los sistemas de conexión directa entre las grandes máquinas productivas, las grandes máquinas de control social y las instancias psíquicas que definen la manera de percibir el mundo" (Guattari y Rolnik 2006, 41), así como el cumplimiento de las demandas de género prescritas por la masculinidad hegemónica ("Capitalismo gore: narcomáquina y performance de género" 04).

Los sicarios "morros" con los que Velázquez cotidianamente se encontraba corresponden a estas espirales de violencia donde - en la mayoría de las ocasiones- se conjugan condiciones de: pobreza/precaridad, frustración, insatisfacción, heroificación criminal y odio (Valencia, "Capitalismo gore" 04) tal como lo podemos constatar aquí: "Si a cualquiera de ellos le hubieran ofrecido por estudiar los mismos dos mil quinientos a la semana que le pagaban los capos, estoy seguro que no abandonarían al narco. La escuela no otorgaba poder: la ranfla, los corridos a todo volumen, el Tecate entre los güevos, la nariz constipada de coca, que los policías te la pelen" (Velázquez 175) Pero como vengo destacando, el encuentro central de su relato será diferente porque corresponderá a la irrupción de un monstruo en el transitar citadino de un ciudadano común junto a su pequeña hija. Una "aparición" testimoniada magistralmente por Velázquez donde se registran las características anómalas y reconfigurativas del asesino serial mexicano.

Me acompañaba mi hija. Salimos del cine a las 9:50 y no había ni un pinche taxi en la calle. Ni siquiera eran las putas diez y la ciudad ya se había dopado. Parecía que se había metido un par de clonazepames y no despertaría en dieciséis horas. Era sábado. Sentí cómo toda mi miseria se me vino encima. Me recriminé por haber sido tan estúpido. Me arrepentí de llevar a la nena a una función que terminara a esa hora. Mi hija me rogó tanto por la película, que fui incapaz de negarme. Debí decirle que no. Debimos esperar al día siguiente. Pero ya ni existía el matiné. Nunca en mi vida me había sentido tan vulnerable. Parado en un bulevar con mi heredera en los brazos, más una cubeta de palomitas y una diadema. "Qué vas a hacer ahora, imbécil”, me preguntaba. "¿Caminar con una niña de cinco años por Torreón a esta hora?” (Velázquez 175-176). 
A partir de ese momento, todo se convertirá en un relato en clave de narrativa sobrenatural. El horror urbano más puro, pero transfigurado y desenmarcado de la ficción, pues estaremos tratando con realidad, con una crónica de sucesos estremecedores. Las calles vacías, el terror por toda la noche, el terror propio con el que la violencia del narco ha impregnado gran parte de las ciudades del norte mexicano y de la mayor parte del territorio nacional. Una esquina solitaria y un padre horrorizado junto a su pequeña hija: "El miedo me había paralizado. Debí llamar a un amigo, a la mamá de mi hija, a un compañero de la oficina, y pedirle que fuera a recogernos. Pero todo me era confuso. Estaba desesperado. Y no podía reaccionar adecuadamente" (Velázquez 176).

El escenario especial para la irrupción del nuevo monstruo mexicano estaba preparado: una ciudad de pulso anormal regulada por el miedo a la muerte, al descuartizamiento, a la vulnerabilidad del cuerpo, de los cuerpos. Los cuerpos de un padre y de una hija en peligro por solo asistir al cine un poco más tarde de la "nueva normatividad" instalada por el asedio de la narcoviolencia:

¿Qué es exactamente un monstruo? Dos condiciones parecen ser necesarias para que exista un monstruo: la anomalía y el peligro. El monstruo implica una irregularidad, una excepcionalidad, algo que representa lo imprevisible asaltando el estado de las cosas. Sin embargo, lo puramente diferente no es monstruoso; el monstruo convoca también un estado de peligro, es algo que no sólo interrumpe el estado de las cosas, sino que además lo amenaza (Paola Cortés-Rocca 340).

Y si el monstruo como figura cultural que es "pura cultura" (según Jeffrey Cohen) ha sido siempre un termómetro súper eficaz de los miedos, de las ansiedades, de las imaginaciones nacionales o sociales; es comprensible que el imaginario cultural del México actual comience a poblarse de estas configuraciones que son altamente ambiguas y sobrecogedoras. Monstruos particulares y singulares de la Narconación mexicana que hibridan el odio y la frustración; monstruosidades que siempre son una mezcla: la pobreza y la muerte, el machismo y la violencia, el cuerpo y su vulneración. Tal como lo expresara Foucault cuando explica sobre "épocas y monstruos":

¿Qué es el monstruo en una tradición a la vez jurídica y científica? Desde la Edad Media hasta el Siglo XVIII que nos ocupa es, esencialmente, la mezcla. La mezcla de dos reinos, reino animal y reino humano, el hombre con cabeza de buey, el hombre con patas de pájaro-monstruos-. Es la mixtura de dos especies, la mezcla de dos especies; el cerdo que tiene cabeza de carnero es un monstruo. Es la mixtura de dos individuos: el que tiene dos cabezas y un cuerpo, el que tiene dos cuerpos y una cabeza, es un monstruo. Es la mixtura de dos sexos: quien es a la vez hombre y mujer es un monstruo. Es una mix- 


\section{Adiós a las armas}

Despatriarcar América desde la cultura

tura de vida y muerte: el feto que nace con una morfología tal que no puede vivir, pero que no obstante logra subsistir durante algunos minutos o algunos días, es un monstruo. Por último, es una mixtura de formas: quien no tiene ni brazos, ni piernas, como una serpiente, es un monstruo. Transgresión, por consiguiente, de los límites naturales, transgresión de las clasificaciones, transgresión del marco, transgresión de la ley como un marco: en la monstruosidad, en efecto, se trata realmente de eso" (68).

"La Mula" el sicario monstruoso que Velázquez y su hija conocerán ese sábado por la noche, configura esa mixtura señalada por Foucault: pulsión de vida y de muerte. Mezcla escalofriante de partes; de cuerpo y cabezas; de lo vivo y de lo muerto. Al menos, eso lo podemos constatar en la representación visual que el ilustrador Israel García Corona preparó para el texto de Velázquez: que también se publicó en la revista Letras Libres:

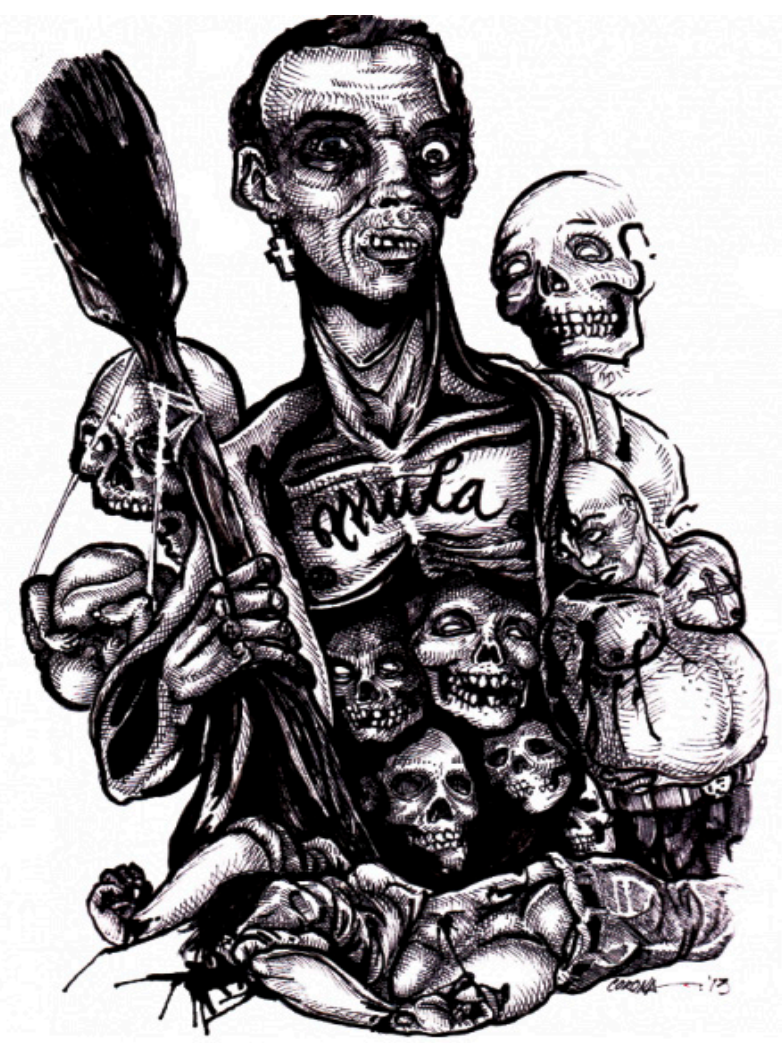

Fig. 2. Ilustración "La Mula” de Israel García Corona. 
Pero, también la negociación de fronteras entre letra e imagen se vuelca hacia lo monstruoso para dar a luz a otra magnífica representación en la propuesta del artista visual Adán Bustillos quien desarrolla la siguiente configuración de "La Mula":

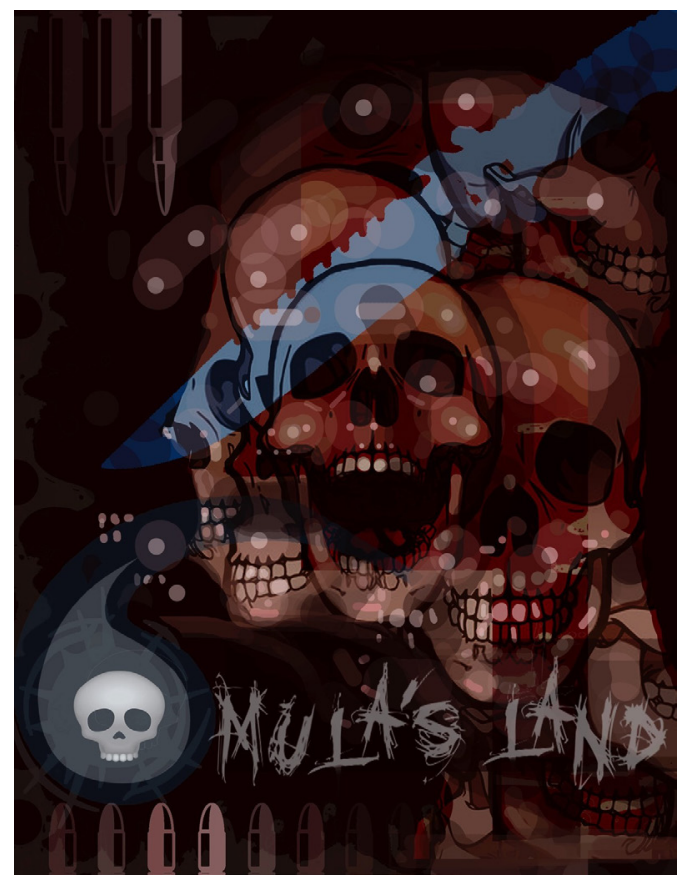

Fig. 3. Ilustración "La Mula" de Adán Bustillos.

En ambas imágenes se constituye el horror que Velázquez plasmó así:

Ese morro era la "Mula". O uno de su tipo. Una especie de chamaquito empleado por el narco como desmembrador. Un informante, ex policía municipal, me había contado sobre estos carniceros de barrio pobre. Se ponían a fumar pintos, soda con mota, o crack, y decapitaban a sus enemigos a cuchillazo limpio. Nada de técnicas sofisticadas. Cables, espadas o mamadas de esas. Destace al estilo marranero. Según el informante, él había presenciado una exhibición de la "Mula". El morrito había descabezado a tres de un tirón en una finca de Francisco I. Madero. "Los Zetas con eso pretendían ofuscarnos", me dijo. "Esto es lo que les va a pasar a todos los que no se alineen, nos amenazaban".

Lo que más me había sorprendido del relato del informante no era la frialdad o la saña para matar del morro, era que bien loco se ponía a hablar con los muertos. "Les platicaba, cuando ya todos nos retirábamos, se sentaba en el piso y les dialogaba". Qué puta locura. A esa edad era para que todavía jugara a las canicas, no tirándole netas a los cadáveres que fabricaba (Velázquez 177). 


\section{Adiós a las armas}

Despatriarcar América desde la cultura

Velázquez le había hecho la parada y subido (junto a su hija) por desesperación a un pseudo taxi que manejaba el joven asesino. Lo identificó de inmediato: olía a sangre seca y estaba totalmente drogado. Un joven de no más de diecisiete años: moreno y enflaquecido por la droga. Aterrorizado, el pasajero de la muerte preguntó el costo del viaje y recibió la siguiente respuesta:

"Mil pesos", me dijo. Y soltó una risa enferma. De hiena. Luego una carcajada macabra. Lo decía en serio. En ese momento se me desprendió el culo y fue a dar hasta el suelo. No me vi en el espejo, pero seguro me puse lívido, porque el cabrón continuó con su pinche risita. El viaje no costaba más de treinta pesos. Le habría dado cien, doscientos. Los mil. No los traía, pero podía sacarlos del cajero. Pero lo que temía es que esos mil fueran en realidad un pretexto para desatar algo que no podría pagar. No con dinero. [] Y ahora estaba encima de ese taxi. Y me sentía un hipócrita. Mejor debí haber muerto de un infarto. Y no poner a mi hija en riesgo. Qué clase de padre era yo si no la podía proteger. Volteé a ver a la nena y un brutal aullido de dolor, como si ya me estuvieran cortando la cabeza, quería escapar de mi garganta. No era producto de mi paranoia. Así es como empiezan las cosas, me decía. Esa petición iba a jodernos pa' siempre. Vinieron a mi memoria todos los anuncios de desparecidas, de niños muertos, y se me partió el alma (Velázquez 178).

Nos testimonia, después, que no contaba con el dinero suficiente para cumplir con las exigencias de "La Mula" algo que lo llevó en distintos momentos a pensar en lo más terrible que pudiera haberle sucedido a él y a su pequeña hija:

"Traigo doscientos", le espeté algo enérgico. Había decidido no discutir con él. No provocarlo. Pero he demostrado que no era mi noche. Me había absorto tanto en mis pensamientos que no me percaté de que estábamos en la esquina de mi casa. Pero de nada servía. Podrían desollarme ahí mismo y mis vecinos no saldrían. [] Abrí la puerta del taxi y le extendí el billete de doscientos. Esto último lo alteró. "Guárdate tu pinche dinero”, me gritó. "No, tómalo", le rogué. "Que te lo guardes", dijo apretando los dientes. Agarré a la niña y le dejé el billete en el asiento. "Qué no entiendes. Llévate tu dinero o quieres que te parta toda tu reputa madre", me amenazó. Lo recogí. "Eh, compa, está linda la morrita", dijo. Lo vi a los ojos por última vez y me bajé con la niña en brazos. Algo pasó en ese cruce de miradas, que no le gustó, porque apenas había caminado como tres metros se bajó del carro. Caminé hacía atrás, hasta repegarme a la pared. Listo por si tenía que bajar a la niña. No sé de dónde la sacó. Pero traía en la mano una tabla de esas que se usan para darle vuelto al cazo de los chicharrones. Venía hacía mí, pero se detuvo justo a la altura de cofre. Las luces de los focos le pegaban en las piernas y en la cintura. Entonces vi todos los muertos que traía cargando. No sé si era un 
efecto de la luz, pero se apreciaba que lo andaban rondando como cuando el sol pega en la atmósfera y revela partículas de polvo (Velázquez 179).

La visión de todos los muertos que cargaba "La Mula" junto a él es una de las visiones más escalofriantes que nos puede ofrecer la crónica testimonial del México de la narcomáquina. Una visión de un país sangriento, mutilado, repleto de cuerpos rotos y cadáveres fragmentados.

Me gustaría comentar -ya cerca de mi conclusión- la otra posibilidad transmedial-transtextual que ofrece el título del relato aquí abordado. Ya que el título también conecta con una imagen por igual de macabra como lo que acabamos de describir o registrar. Proviene de un cartel propagandístico utilizado por el bando republicano durante la Guerra Civil Española. Es un cartel que funcionó para mover los afectos a través del horror y hacerse del apoyo internacional. En la imagen aparece el cadáver de un niño asesinado por los bombardeos del bando nacionalista y hacía un llamado a sumarse a la lucha, pues si el mundo toleraba esto, sus hijos serían los siguientes. La imagen es por demás sobrecogedora:

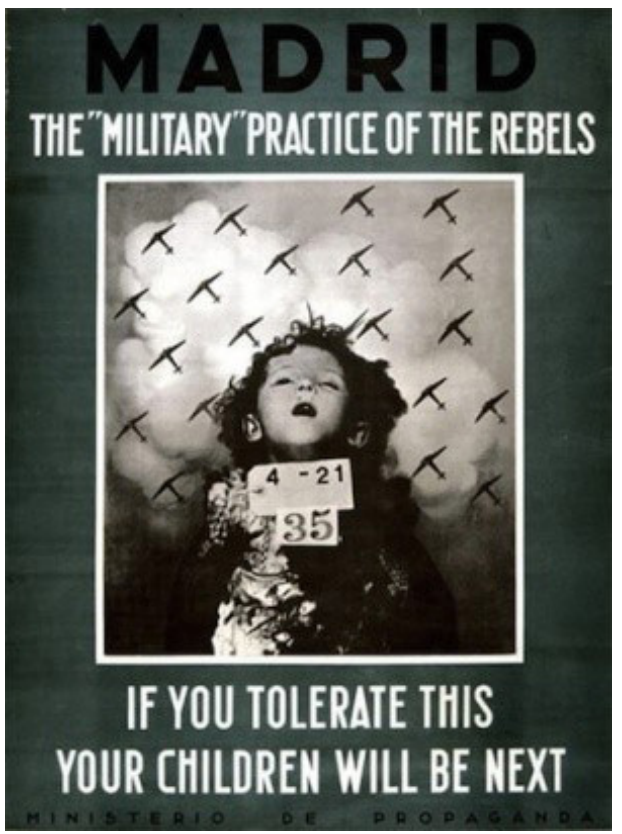

Fig. 3. Ilustración "La Mula" de Adán Bustillos.

Inicié este trabajo desde la reflexión de las terribles imágenes de un niño disfrazado de sicario monstruoso y asesino en este 2019 en Sinaloa, México; una imagen que también me llevó a recordar los fatídicos acontecimientos de mayo del 2015 en la colonia Laderas de San Guillermo de la ciudad de Chihuahua. Sin duda creo que algo debemos hacer para que las violencias monstruosas no nos 


\section{Adiós a las armas}

Despatriarcar América desde la cultura

susurren terroríficamente al oído: “Tus niños son los siguientes”. La persistencia crítica es una de esas labores que desde la academia podemos continuar realizando. Un gesto alegórico, como ya otros y otras han expresado. Un gesto de mirar a la Medúsa monstruosa de nuestros contextos como lo hiciera Perseo: la imagen escudo del horror. 


\section{Obras citadas}

Aristegui Noticias. "Tragedia en Chihuahua: jugaban al secuestro con un niño de seis años y lo matan”. Aristegui Noticias, 16 mayo 2015, https://aristeguinoticias.com/1605/mexico/ tragedia-en-chihuahua-jugaban-al-secuestro-con-un-nino-de-seis-anos-y-lo-matan/

Cortés-Rocca, Paola. "Etnología ficcional. Brujos, zombis y otros cuentos caribeños". Revista Iberoamericana, vol. lxxv, no. 227, 2009, pp. 333-347.

Foucault, Michel. Los anormales. Fondo de Cultura Económica, 2011.

Guerrero, Vladimir. "Hibridaciones y desterritorialización: entre el horror sobrenatural y la narcoviolencia mexicana. Imágenes-Monstruo: Narcozombies en la novela Ciudad de Zombis de Homero Aridjis". Configuraciones del desvió. Estudios sobre lo fantástico en la literatura latinoamericana, editado por Claudio Paolini, Marcelo Damonte y Virginia Frade, Tenso Diagonal Ediciones/Díaz Grey, 2017.

Giorgi, Gabriel. "Política del Monstruo". Revista Iberoamericana, vol. lxxv, no. 227, 2009, pp. 323-329.

Halberstam, Judith. Masculinidad femenina. Egales, 2008.

"Niños juegan a ser Sicarios y Matan a niño en Chihuahua, México". Dailymotion, 2015, https://www.dailymotion.com/video/x3cwdly

Valencia, Sayak. "Capitalismo gore: narcomáquina y performance de género". E-Misférica, no. 8.2, 24 agosto 2015, http://archive.hemisphericinstitute.org/hemi/es/e-misferica-82/ triana

Valencia, Sayak. Capitalismo gore. Melusina, 2010.

Valencia, Sayak. "Teoría transfeminista para el análisis de la violencia machista y la reconstrucción no violenta del tejido social en el México contemporáneo". Revista Universitas Humanistica, no. 78, 2014, pp. 65-88.

Velázquez, Carlos. El karma de vivir al norte. Sexto Piso, 2013.

Velázquez, Carlos. "If you tolerate this your children will be next". Letras Libres, 27 agosto 2013, https://www.letraslibres.com/mexico-espana/if-you-tolerate-your-children-willbe-next 